\title{
High Winds at Nygårdsfjell
}

\author{
Muhammad Bilal, Yngve Birkelund, and Matthew Homola
}

\begin{abstract}
Wind energy in cold climate offers challenges that include among others, the icing on the turbine blades that affects the power output of the turbines. We investigate the presence of high winds at the Nygårdsfjell wind farm that is situated in north of the Arctic Circle in Norway. The data is taken from three 2.3 MW Siemens wind turbines (SWT-2.3-93) that were installed at Nygårdsfjell during the fall of 2005. There are total of 185 high winds events detected consisting of 1737 hours during the observation period May 2008 until April 2009. Out of these 1737 hours of high winds, 269 hours occurred during May 2008 until October 2008 and 1468 hours occurred during November 2008 until April 2009 that is $84.5 \%$ of total high winds hours. That shows the majority of high winds events occurring during the colder periods. The ten leading high winds events showed the presence of wind speeds ranging from $16 \mathrm{~m} / \mathrm{s}$ to $19 \mathrm{~m} / \mathrm{s}$ with maximum up to $24 \mathrm{~m} / \mathrm{s}$. The analysis established the existence of high winds at Nygårdsfjell during colder times.
\end{abstract}

Index Terms - High winds, Nygårdsfjell, wind energy in cold climate.

\section{INTRODUCTION}

Cold climate regions have unique environment conditions, which are considerably different from other parts of the world. International Energy Agency (IEA) - Task XIX Wind Energy $R \& D$ has been formed to develop effective technologies by learning from the shared experiences of operating wind farms in cold climates around the world. Normally the power output of a wind turbine is mainly dependent on the wind speed. In cold climates, other factors such as low temperatures and icing influence the power output as well. A recent report forecasts large wind potential in cold climates and predicts between 45 and 50 gigawatts of wind energy to be built by 2017 [1]. That emphasizes the importance of understanding the challenges presented by cold climate. The most important issues among others for wind turbines in icing climate are: performance losses due to rime ice protrusion, power losses due to disrupted aerodynamics [2], increased fatigue due to icing [3] and damage done by shedding of ice [4]. The annual power losses on slightly ice affected sites are reported up to $1-10 \%$ and under harsh conditions up to $20-50 \%$ [5]. The Nygårdsfjell wind farm is located in a valley at approximately 420 meters above sea level surrounded by mountains in the

Manuscript received January 29, 2014; revised May 24, 2014. The project is a part of ongoing collaboration between the Arctic University of Norway (Uit), Nordkraft Vind and Meteorologisk Institutt Norway.

Muhammad Bilal is with Department of Physics and Technology at the Arctic University of Norway (Uit), 9037 Troms $\varnothing$ Norway (e-mail: muhammad.bilal@uit.no).

Yngve Birkelund is with Department of Engineering and Safety at the Arctic University of Norway (Uit), 9037 Troms $\varnothing$ Norway (e-mail: yngve.birkelund@uit.no).

Matthew Homola is with Nordkraft Vind, Narvik, Norway (e-mail: matthew.homola@Nordkraft.no). north and south near the Swedish border. Its location makes it a natural candidate for research concerning wind energy in cold climate.

In this paper we investigate the existence of high winds at the Nygårdsfjell wind farm. These winds are suspected to be originating from Torneträsk Lake in east which is covered with ice during the winter time. The air closest to the surface on surrounding mountains gets colder and denser. The air then slides down the hill and accumulates over the lake. The air then spills out westward towards Ofotfjord through the broader channel that directs and transforms it into speeding winds.

A brief geographical location of the wind farm is discussed along with data description. The data is filtered and analyzed for values which correspond to wind speeds $(\mathrm{V},[\mathrm{m} / \mathrm{s}])$ greater than $12 \mathrm{~m} / \mathrm{s}$. At the end, results are discussed establishing the existence of high winds at Nygårdsfjell.

\section{METHOD}

\section{A. Site and Data Description}

The Nygårdsfjell wind farm is located in a valley at approximately 420 meters above sea level with mountains up to 2000 meters in north and south. A mountainous terrain with lower gradient goes east towards Torneträsk Lake, a 330 square kilometer lake that also acts as a natural wind channel, and is surrounded by higher mountains predominantly in north and south. The lake is usually covered with ice from December through June. During periods of clear skies, radiant heat loss causes the surface air on surrounding mountains to become colder and denser. The heavier air slides down to the base of the lake. The accumulated air spills towards the Ofotfjord, 9 kilometer south-west of Nygårdsfjell. The local terrain boosts and directs the winds that eventually fade away into Ofotfjord. Ofotfjord is ice-free and relatively warm during the winter due to the Gulf Stream. Fig. 1 shows the location of the wind farm as indicated by the tower symbol.

The data is taken from three 2.3 MW Siemens wind turbines (SWT-2.3-93) that were installed at Nygårdsfjell during fall of 2005. The turbine foundation is at 420 meters above sea level with a tower height of 80 meters that puts the nacelle height at 500 meters above sea level. The nacelle is installed with a thermostat controlled heated anemometer. It is difficult to expect that the nacelle anemometer gives accurate free streaming values of wind speed as specified in IEC standard, but the measurements are sufficient enough for the detection of significant variation in wind speed [6], [7]. The wind turbine log files record a range of data including, but not limited to: wind speed, yaw position [degree], ambient temperature $\left(\mathrm{T},\left[{ }^{\circ} \mathrm{C}\right]\right)$, blade pitch angle [degree] and power $(\mathrm{P},[\mathrm{kW}])$. The data is recorded as 10 minute average values 
and is for the period of May 2008 to April 2009. The data is filtered according to the pitch angle and cleaned of corrupted points as well as for the off time periods. Meteorological data is extracted using the HIRLAM 4 model at four surrounding points and time synchronized with the measured data. The extracted data consists of a range of forecast values including but not limited to wind speed, wind direction [degree], ambient temperature, and mean sea level pressure (Pressure, $[\mathrm{mb}])$.

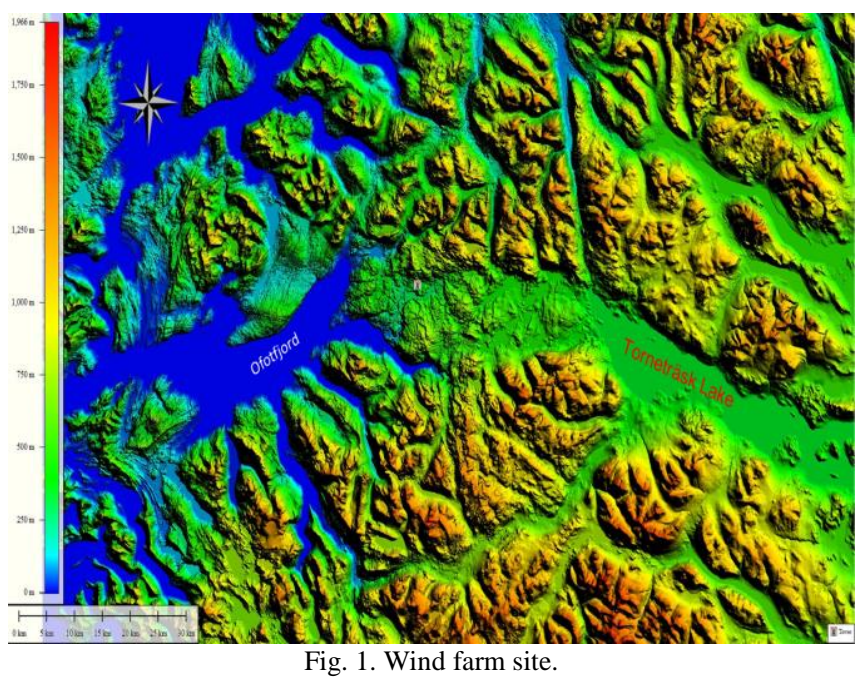

\section{B. Geophysical Parameters}

The most important parameters discussed are the wind speed, the ambient temperature, the mean sea level pressure and the local terrain. Heywood discussed the influence of low ambient temperatures on downslope winds and how these winds are observed during very low temperatures [8]. Although mean sea level pressures do not capture the variations in pressure due to mountain waves, nevertheless it gives an idea of the overall influence of pressure gradients on wind direction. Ball discussed how the role of local terrain shapes the direction of these winds along with boosting their speed. The pressure gradient and local terrain assist in directing these winds [9].

\section{RESULTS}

We investigate the existence of high winds at the Nygårdsfjell wind farm. One of the most important analyses is to figure out the duration of these high winds. A significant duration directly influences the overall output of the wind farm. The data is converted into hourly averages, which are then used for the entire analysis. All the data points with winds speed greater than $12 \mathrm{~m} / \mathrm{s}$ are referred to as high winds and their occurrences are called high winds events. The reason to select the wind speed of $12 \mathrm{~m} / \mathrm{s}$ as a threshold value is that the installed wind turbines generate approximately $87 \%$ of their rated power at this wind speed. A yearly plot of the overall wind speeds and their directions is shown in the in Fig. 2. The majority of the high winds are coming from the east, between 90 degrees to 100 degrees as indicated by the data points above the threshold line.

Monthly analysis gives valuable insights into high winds behavior. In order to capture the important variations during high winds events, separate monthly mean values of wind speeds are calculated. One mean value corresponds to only high winds and the other is overall mean value of the wind speed during the month. These two mean values are plotted together in Fig. 3. This way the variations within high winds periods, indicated by red bars, are studied in a better way without having them suppressed into the overall monthly mean values.

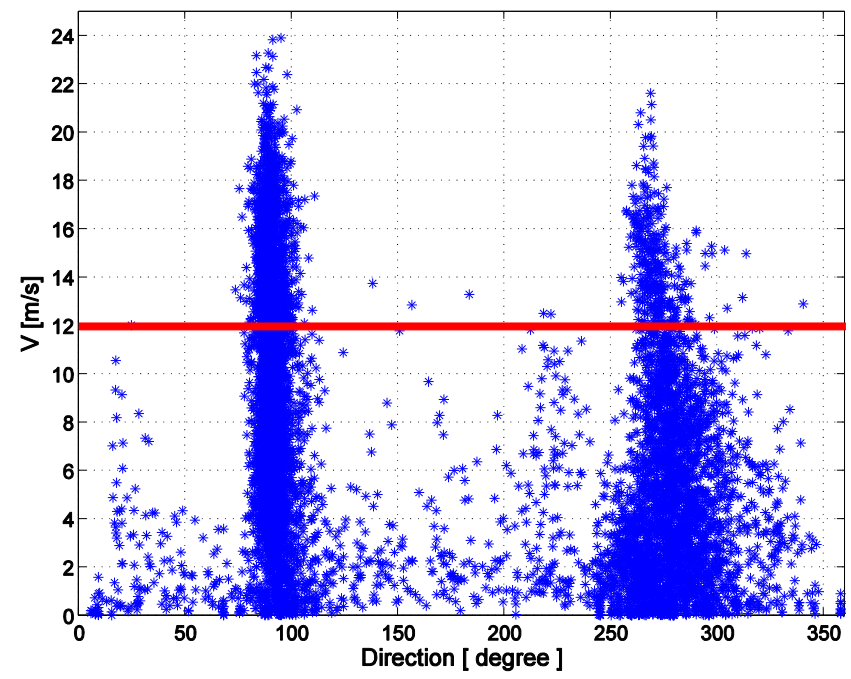

Fig. 2. Hourly values of wind speed and direction - May '08 till April '09.

For the month of July 2008, about $39 \%$ of the data was corrupted and no high winds events were detected from the rest of the valid data. In February 2009 the overall mean wind speed for the month is just over $10 \mathrm{~m} / \mathrm{s}$ but the mean wind speed during the high winds events is well over $15 \mathrm{~m} / \mathrm{s}$. The next step is to quantify these high winds during each month. Frequency of occurrences of these high winds indicates how significant of a role they play in the overall power output of the wind farm.

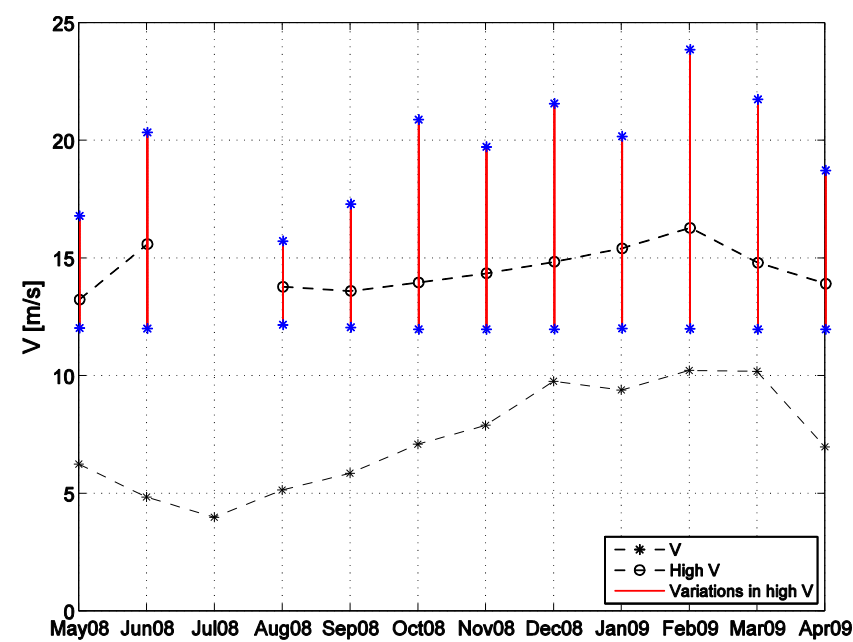

Fig. 3. Monthly high winds variations.

The monthly frequency of occurrences of high winds events is shown in Fig. 4. As mentioned before, high winds occurred mostly during cold periods with low ambient temperatures. Nylen stated that the downslope winds are not only more frequent in winters than summers but also stronger 
[10]. February 2009 experienced the highest occurrence of almost $45 \%$, that constitutes roughly 302 hours of high winds events out of 672 hours. January and March 2009 experienced around $40 \%$ of high winds. A model for predicting such events in advance would increase the overall efficiency of installed wind turbines. In order to model the event it is important to closely study the variations in wind speed, wind direction, ambient temperature and pressure. Pressure gradient might be an important indicator of the influence of pressure on dominating wind direction during these events. There are no available measurements for the pressure values either at the wind farm or at the surrounding locations. Values of wind speed, wind direction and ambient temperature are taken from the wind farm data log; whereas pressure values are extracted by using the meteorological model HIRLAM 4 towards east and west directions from the wind farm. Pressure gradient between the points, distant at 100 kilometers, is calculated from east to west. It is important to state that the extracted pressure values are the mean sea level pressure (mslp) values. The model does not take into account the local geographical terrain and hence does not capture the variations in pressure due to mountain waves. Nonetheless the variations in pressure gradient indicate its influence in shaping these high winds.

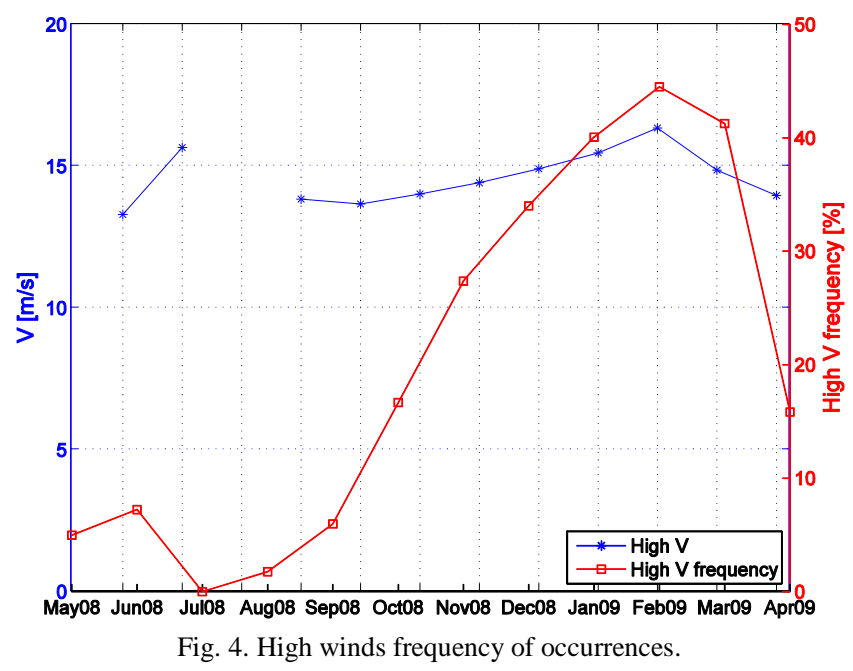

Fig. 5 shows a typical high wind event that started at 07.11.2008 16:00 and finished at 08.11.2008 11:00 after lasting for 20 hours. As the wind speed approached $12 \mathrm{~m} / \mathrm{s}$, the wind direction changed from west to east indicating the origin of higher winds in east. The pressure gradient continued increasing before and during the event, indicating the relative presence of higher pressure in the east. The pressure gradient decreased sharply near the end of the event marking the relative lower pressure in the east. The increased pressure gradient before the event facilitated the change in wind direction. The local terrain as well played its role in boosting and concentrating the wind speed and its direction. The ambient temperature kept decreasing during the event indicating the presence of colder winds coming from the east. The ambient temperature began increasing again once the wind speeds started to slow down. The wind direction started to change at the end of the event with a decrease in pressure gradient. Modelling of the event requires further research into all the parameters involved and their behavior during different time instances and under different climate conditions.
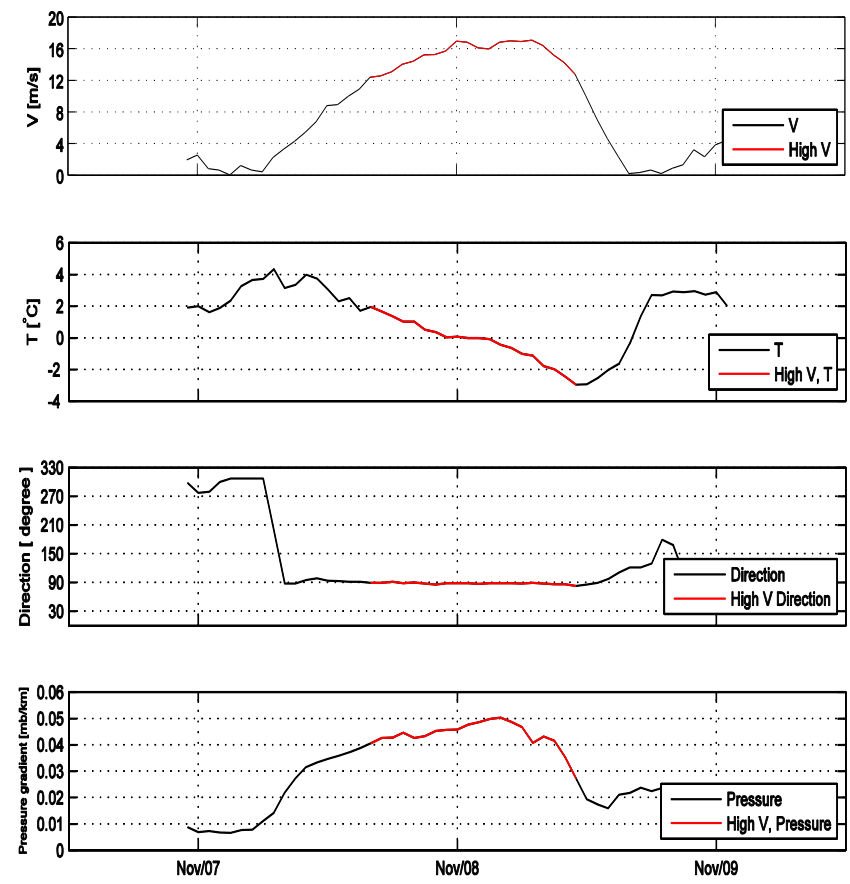

Fig. 5. A typical high wind event.

Table I summarizes the ten leading high winds events in descending order of wind speed. High winds are ranging from $16 \mathrm{~m} / \mathrm{s}$ to $19 \mathrm{~m} / \mathrm{s}$ with a maximum up to $24 \mathrm{~m} / \mathrm{s}$. It is evident that almost all of the high winds events occurred during cold periods as highlighted in bold. The most probable time of such events were reported to be any time after the sunset. Nygårdsfjell is situated in the Arctic Circle so during winter time there is no sun for a couple of months. The low ambient temperatures during winters further facilitate the downslope winds. The most probable time of drainage winds are stated as after sunset [11]. There are a total of 185 high winds events retrieved, consisting of 1737 hours. Out of these 185 events, 49 events equaling 269 hours occurred during May 2008 until October 2008 and 136 of the events corresponding to 1468 hours occurred during November 2008 until April 2009. It shows that autumn and winter seasons experienced the most number of high winds events. The direction of these high winds is categorized in such a way that all the high winds between 70 to 110 degrees are considered easterly winds whereas westerly winds are between 250 to 290 degrees. Easterly winds constitute around 1418 hours out of a total of 1737 hours that is $81.6 \%$. That endorses our earlier impression that downslope winds come from Torneträsk Lake in the east. The wind direction gets concentrated from one direction due to local terrain and orography. The duration of each individual event is also calculated. The highest duration of a single event is recorded as 105 hours; that is almost 4 and one half days. The observed temperatures show that all of the high winds events occurred during very low ambient temperatures. That also has a direct influence on the power output of the turbines. Higher than expected power output during low ambient temperatures is reported in similar climate [12]. 
TABLE I: HIGH WINDS EVENTS

\begin{tabular}{|c|c|c|c|c|c|}
\hline Start Date & $\begin{array}{c}\text { Duration } \\
{[\text { hours }]}\end{array}$ & $\begin{array}{c}\mathrm{V} \\
{[\mathrm{m} / \mathrm{s}]}\end{array}$ & $\begin{array}{c}\text { Max. } \\
\text { V }[\mathrm{m} / \mathrm{s}]\end{array}$ & $\begin{array}{c}\text { Direction } \\
{[\text { degrees }]}\end{array}$ & $\begin{array}{c}\mathrm{T} \\
{[\mathrm{C}]}\end{array}$ \\
\hline $\mathbf{0 4 . 0 2 . 2 0 0 9}$ & $\mathbf{2 6}$ & $\mathbf{1 8 . 8 6}$ & $\mathbf{2 3 . 8 9}$ & $\mathbf{8 9 . 7 4}$ & $\begin{array}{c}\mathbf{- 1 1 . 6} \\
\mathbf{0}\end{array}$ \\
\hline $\mathbf{0 5 . 0 2 . 2 0 0 9}$ & $\mathbf{9 4}$ & $\mathbf{1 7 . 6 4}$ & $\mathbf{2 3 . 1 6}$ & $\mathbf{9 3 . 2 2}$ & $\begin{array}{c}\mathbf{- 1 8 . 8} \\
\mathbf{2}\end{array}$ \\
\hline $\mathbf{2 5 . 1 2 . 2 0 0 8}$ & $\mathbf{3 1}$ & $\mathbf{1 7 . 3 0}$ & $\mathbf{2 1 . 6 0}$ & $\mathbf{2 7 0 . 2 0}$ & $\mathbf{- 3 . 7 2}$ \\
\hline $\mathbf{0 8 . 0 3 . 2 0 0 9}$ & $\mathbf{8 3}$ & $\mathbf{1 6 . 8 4}$ & $\mathbf{2 1 . 7 7}$ & $\mathbf{8 9 . 7 8}$ & $\mathbf{- 6 . 1 9}$ \\
\hline $\mathbf{2 7 . 1 1 . 2 0 0 8}$ & $\mathbf{2 1}$ & $\mathbf{1 6 . 8 1}$ & $\mathbf{1 9 . 7 6}$ & $\mathbf{9 1 . 2 8}$ & $\mathbf{- 4 . 3 8}$ \\
\hline $\mathbf{1 7 . 0 2 . 2 0 0 9}$ & $\mathbf{8 2}$ & $\mathbf{1 6 . 7 7}$ & $\mathbf{2 1 . 0 0}$ & $\mathbf{8 8 . 2 3}$ & $\mathbf{- 1 4 . 2}$ \\
& & & & & $\mathbf{4}$ \\
\hline $\mathbf{1 7 . 0 1 . 2 0 0 9}$ & $\mathbf{1 0 5}$ & $\mathbf{1 6 . 6 9}$ & $\mathbf{2 0 . 1 7}$ & $\mathbf{8 9 . 3 0}$ & $\mathbf{- 7 . 3 4}$ \\
\hline $\mathbf{2 3 . 0 1 . 2 0 0 9}$ & $\mathbf{5 9}$ & $\mathbf{1 6 . 4 2}$ & $\mathbf{2 0 . 2 0}$ & $\mathbf{8 8 . 7 1}$ & $\mathbf{- 6 . 9 9}$ \\
\hline $\mathbf{1 4 . 1 2 . 2 0 0 8}$ & $\mathbf{2 5}$ & $\mathbf{1 6 . 2 0}$ & $\mathbf{1 8 . 0 5}$ & $\mathbf{8 8 . 4 5}$ & $\mathbf{- 8 . 0 5}$ \\
\hline 05.01 .2009 & 28 & 16.18 & 20.91 & 93.56 & 1.79 \\
\hline
\end{tabular}

\section{CONCLUSION}

November 2008 till April 2009 experienced around 84.5\% of the total high winds blown in the entire observation period. This, along with previous analysis establishes the existence of high winds at Nygårdsfjell during winter times.

To further investigate the nature of these high winds, a detailed field measurement survey is planned in February March 2014. Unmanned Aerial Vehicle (UAV) measurements will be used for wind profiling. Low production losses have been observed at Nygårdsfjell in spite of icing. It will be interesting to investigate whether or not the presence of high winds are linked with such an observation.

\section{ACKNOWLEDGMENT}

Gratitude is extended to Nordkraft Vind for granting access to their data and to Meteorologisk Institutt Norway for providing meteorological parameters.

\section{REFERENCES}

[1] BTM Consult ApS, "International wind energy development: World market update 2012: forecast 2013-2017," Navigant Consulting, 2013.

[2] W. J. Jasinski, S. C. Noe, M. S. Selig, and M. B. Bragg, "Wind turbine performance under icing conditions," Transactions-American Society of Mechanical Engineers Journal of Solar Energy Engineering, vol. 120 , pp. 60-65, 1998 .

[3] P. Frohboese and A. Anders, "Effects of icing on wind turbine fatigue loads," Journal of Physics: Conference Series, vol. 75, pp. 12-61, 2007.

[4] H. Seifert, A. Westerhellweg, and J. Kröning, "Risk analysis of ice throw from wind turbines," Boreas, vol. 6, no. 9, 2003.

[5] B. Tammelin, C. Morgan, E. Peltola, F. Richeft, H. Siefert, K. Säntti, and P. Volund, "Wind energy production in cold climate," in Proc. EWEC Conference, 1997, pp. 347-353.

[6] M. C. Homola, "Atmospheric icing on wind turbines," PhD thesis, Norwegian University of Science and Technology, Department of Engineering Cybernetics, 2011.

[7] M. C. Homola, P. J. Nicklasson, P. A. Sundsbø, and A. E. Holdo, "Experiences from icing at Nygårdsfjell wind park," in Proc. the EWEC Conference, 2008.

[8] G. S. P. Heywood, "Katabatic winds in a valley," Quarterly Journal of the Royal Meteorological Society, vol. 59, no. 248, pp. 47-58, 1933.

[9] F. K. Ball, "The theory of strong katabatic winds," Australian Journal of Physics, vol. 9, no. 3, pp. 373-386, 1956.

[10] T. H. Nylen, A. G. Fountain, and P. T. Doran, "Climatology of katabatic winds in the McMurdo dry valleys, southern victoria land, Antarctica," Journal of Geophysical Research: Atmospheres, vol. 109, issue D3, 2004.

[11] Z. Petkovśek and A. Hoćevar, "Night drainage winds," Archiv für Meteorologie, Geophysik und Bioklimatologie, Serie A, vol. 20, no. 4 pp. 353-360, 1971.

[12] C. Leclerc and C. Masson, "Abnormally high power output of wind turbine in cold weather: A preliminary study," International Journal of Rotating Machinery, vol. 9, no. 1, pp. 23-33, 2003.

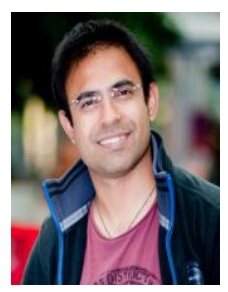

Muhammad Bilal received his bachelor of Sci. degree in electrical telecommunication from National University of Computer and Emerging Sciences, Lahore, Pakistan, in 2007. He graduated in master of Eng. degree in technical management from Germany in 2009 and received the second master of Eng. degree in renewable energy systems from Germany in 2011 $\mathrm{He}$ is currently a Ph.D. candidate in the Department of Physics and Technology at the Arctic University of Norway (Uit). He received the Student Paper Award at the Alternative Energy Presentation Contest - Young Engineers, Kuwait, in 2009. His research interests are in the areas of short term wind power prediction in the Arctic with emphasis on numerical modeling and performance analysis. 

Bioenergy 
